\title{
Soil Nitrification Potential Influences the Performance of Nitrification Inhibitors DCD and DMPP in Cropped and Non-Cropped Soils
}

\author{
Hussnain Mukhtar and Yu-Pin Lin *(D) \\ Department of Bioenvironmental Systems Engineering, National Taiwan University, Taipei 10617, Taiwan; \\ agricultureenvironment33@gmail.com \\ * Correspondence: yplin@ntu.edu.tw; Tel.: +886-3366-3468
}

Received: 24 August 2019; Accepted: 27 September 2019; Published: 29 September 2019

\begin{abstract}
The application of nitrification inhibitors (NIs) shows promise in prolonging the ammonium presence in soil with beneficial effects for agriculture ecosystems and climate change mitigation. Although the inhibitory effect (IE) of NIs has been studied in the presence of various environmental and edaphic conditions, little is known about the effect of soil nitrification potential (NP) on the effectiveness of NIs. Here, laboratory-scale experiments were conducted to investigate the effect of the variation in soil NP rates, among land-use type and temperature, on the performance of two nitrification inhibitors, dicyandiamide (DCD) and 3,4-dimethypyrazole phosphate (DMPP), at four NI application rates imposed upon eight cropland and non-cropland soils. We found that the IE of DCD and DMPP were organized according to soil NP rates. Nevertheless, NP was lower in non-cropped soil than in cropped systems, and DMPP-based inhibition was higher than DCD. The IE of both NIs decreased with NP and the amount of NI required to achieve an IE $\approx 50 \%$, was significantly reduced for soils that exhibited the lowest NP rates, especially for DMPP. However, the temperature did not appear to have a major influence on IE of both DCD and DMPP, demonstrating the potential of NIs to inhibit nitrification for a wider temperature range, dependent on the NI application rate. Our findings provide evidence that change in soil NP rate has important influences on the efficacy of NI which required great consideration for N-fertilizer optimization with the application of nitrification inhibitors.
\end{abstract}

Keywords: DCD; DMPP; nitrification; soil; temperature

\section{Introduction}

Nitrogen-based fertilizers are widely used in agriculture soils to meet the increasing demand for greater agricultural production around the globe. However, ammonia/ammonium, in excess of plant demand, is reduced to other forms of nitrogen through nitrification and denitrification processes, which increases greenhouse gas emission (i.e., nitrous oxide $\left(\mathrm{N}_{2} \mathrm{O}\right)$ ) and nitrogen leaching from the root zone [1]. Nitrification is the biological oxidation of ammonia or ammonium to nitrite $\left(\mathrm{NO}_{2}{ }^{-}\right)$, and further oxidation to nitrate $\left(\mathrm{NO}_{3}{ }^{-}\right)$with the help of ammonia-oxidizing archaea (AOA) and bacteria $(\mathrm{AOB})$, and nitrite-oxidizing bacteria (NOB) [2,3]. During the nitrification process, nitrous oxide $\left(\mathrm{N}_{2} \mathrm{O}\right)$ can be produced as an intermediate and be liberated into the atmosphere [4]. Moreover, $\mathrm{NO}_{3}{ }^{-}$produced from the nitrification process and used as an electron acceptor with organic carbon through the denitrification process, further produces gaseous nitrogen compounds including $\mathrm{N}_{2} \mathrm{O}$ [5]. Therefore, it is often desirable to manage the nitrification process to enhance N-fertilizer use efficiency in agriculture systems, as well as to reduce greenhouse gas emissions, especially in agricultural systems where fertilizer is often applied as ammonia or in organic form as slurry [6]. 
In recent decades, nitrification inhibitors (NIs) such as 3,4-dimethylpyrazole phosphate (DMPP) and dicyandiamide (DCD) have been widely used to reduce N-loss and to improve N-use efficiency in a wide variety of soil that vary from fertilized agriculture to pasture soils [7-13]. NIs can be divided into two groups based on their modes of action: the first group of NIs that suppresses the oxidation of $\mathrm{NH}_{3}$ to $\mathrm{NO}_{2}{ }^{-}$, and a second group that inhibits the conversion of $\mathrm{NO}_{2}{ }^{-}$to $\mathrm{NO}_{3}{ }^{-}$. DCD and DMPP belong to the first group of NIs which retard the first stage of nitrification process by 1) binding and interacting with the ammonia monooxygenase enzyme (AMO) [14], and 2) behaving as metal chelators by removing copper $(\mathrm{Cu})$ which is a co-factor of ammonium monooxygenase [15].

Regarding the inhibition effect of DCD and DMPP, previous studies suggest an application rate, of DCD $\geq 5 \mathrm{~kg} \mathrm{NI} \mathrm{ha}^{-1}$ and DMPP $\geq 1 \mathrm{~kg} \mathrm{NI} \mathrm{ha}^{-1}$, is necessary for an efficient $\mathrm{N}_{2} \mathrm{O}$ reduction in various grassland and agriculture soils [7,16-24]. Moreover, the effectiveness and persistence of these NIs are associated with temperature [20], and other soil processes (i.e., mineralization, microbial assimilation, sorption) and therefore, to environmental and edaphic properties [7,25-30]. The picture that emerges from these studies is that the persistence of both DCD and DMPP varies from a few weeks to months, depending upon the soil temperature [7,31]. Specifically, higher sorption and microbial assimilation for DCD, and lower degradability of DMPP in soil have also been reported [32,33]. Moreover, both DCD and DMPP are considered to mainly inhibit the activity of AOB, rather than AOA, in different soils $[34,35]$. Although previous studies help to understand the interaction between the inhibitory effect (IE) of NIs and soil properties, it remains poorly understood how soil nitrification potential influences the effectiveness of DCD and DMPP in inhibiting ammonia oxidization in soil.

Soil nitrification is highly context-specific in that the process varies between environmental and edaphic factors that control nitrifier abundances and composition, and their activities in soil [36-39]. On the other hand, soil nitrification is highly sensitive to temperature so that nitrification rates increase with increasing temperature, and sharply decrease to above the optimum temperature at which maximum activity can be observed due to enzyme degradation at high temperature in soil $[3,40,41]$. Therefore, these variations in soil nitrification potential (NP) among different soils and temperatures would require different application rates of DCD and DMPP to achieve the substantial inhibition of ammonia oxidization in soil. Although few prior studies have investigated the correlation between soil nitrification rates and DCD and DMPP performance, they have found a decrease in IE with increasing soil nitrification rate though the results are mostly based on limited application rates of DCD and DMPP [42,43]. Moreover, most studies used a narrow range of temperature and a long incubation period to incubate the soil after the application of NIs, which affect the persistence of NIs in soil, making it difficult to understand the variation in NI performance as influenced by variation in soil NP rates. Therefore, we aimed to study the influence of altering soil NP rates on the efficiency of four application rates of DCD and DMPP within a temperature range from $17^{\circ} \mathrm{C}$ to $37^{\circ} \mathrm{C}$, imposed upon eight different cropped and non-cropped soils collected from four different counties in Taiwan.

\section{Materials and Methods}

\subsection{Soil Sampling}

The soil samples, representing different soil types from different climate regions of Taiwan [41], were collected from cropped land and non-cropped land across four different counties including Chiayi, Taoyuan, Miaoli, and Pingtung. Six to eight soil samples from each site were collected randomly at depths of approximately $15 \mathrm{~cm}$ and a composite sampling technique was used to represent each sampled field. Further, samples were sieved to standardize a $<3 \mathrm{~mm}$ particle size and stored at $4{ }^{\circ} \mathrm{C}$ for further physicochemical analysis.

The cropped land usually follows a rice-wheat cropping cycle, which has been cultivated for more than a decade. The soil is slightly acidic ( $\mathrm{pH} 5.62-7.23$ ) with 1.47 to $2.21 \mathrm{~g} \mathrm{~kg}^{-1}$ of total nitrogen and 9.92 to $12.74 \mathrm{~g} \mathrm{~kg}^{-1}$ of total organic carbon. On other hands, non-cropped soil is composite of forest and fallow lands with no significant difference in $\mathrm{pH}$ range (5.87-6.69) and a relatively lower total 
nitrogen (TN) which varies from 1.13 to $1.72 \mathrm{~g} \mathrm{~kg}^{-1}$ compare to cropped soils. However, non-cropped soil showed relatively higher level of total organic carbon (TOC) $\left(12.45 \pm 2.92 \mathrm{~g} \mathrm{~kg}^{-1}\right)$ than cropped soils. However, there was no significant difference between cropped and non-cropped soils for edaphic properties. Full detail of soil properties can be found in Supplementary Material (Table S1).

\subsection{Soil Incubation and Nitrification Potential Measurement}

We carefully selected the temperature range from $17^{\circ} \mathrm{C}$ to $37^{\circ} \mathrm{C}$ because this range provides the optimum temperature for nitrification activity carried out by both $\mathrm{AOA}$ and $\mathrm{AOB}$, and also represents the temperature range often used in recent studies to inhibit nitrification in different agriculture and pasture soils $[7,25,26]$. A total of 288 different scenarios were studied representing four different concentrations of DCD and DMPP $\left(0.2 \mathrm{mg} \mathrm{kg}^{-1}, 0.6 \mathrm{mg} \mathrm{kg}^{-1}, 1.2 \mathrm{mg} \mathrm{kg}^{-1}\right.$, and $1.8 \mathrm{mg} \mathrm{kg}^{-1}$ of dry soil, respectively), with a control (no application of NIs) incubated at four different temperatures $\left(17^{\circ} \mathrm{C}, 23{ }^{\circ} \mathrm{C}, 30^{\circ} \mathrm{C}\right.$, and $\left.37^{\circ} \mathrm{C}\right)$, imposed upon eight cropland and non-cropland soils exhibiting different soil nitrification responses. The soil NP rates were determined by exposing the (autotrophic) ammonium-oxidizer to ammonium sulfate $\left(\left(\mathrm{NH}_{4}\right)_{2} \mathrm{SO}_{4}\right)$ of moist soil slurry buffered at $\mathrm{pH}$ 7.2.

An appropriate concentration of substrate (ammonium sulfate), which can provide an adequate amount of ammonium for $\mathrm{AOA}$ and $\mathrm{AOB}$ during the incubation period, and optimum concentration of Sodium chlorate $\left(\mathrm{NaClO}_{3}\right)$ to inhibit the oxidation of the nitrite was used as described in our previous study [41]. Mukhtar et al. (2019) found no significant $\mathrm{NO}_{2}{ }^{-}$accumulation over $24 \mathrm{~h}$ above $200 \mathrm{mg} \mathrm{L}^{-1}$ of $\left(\mathrm{NH}_{4}\right)_{2} \mathrm{SO}_{4}$ where $\mathrm{NO}_{3}$ production was negligible above $7.5 \mathrm{mmol} \mathrm{L}-1$ of $\mathrm{NaClO}_{3}$. A minimum and maximum concentration of DCD and DMPP, at which $>1 \%$ and approximately $50 \%$ nitrification inhibition can be observed at $30^{\circ} \mathrm{C}$ and $37^{\circ} \mathrm{C}$, was determined by a series of additional experiments. These temperatures were selected since 1) the highest nitrification rate is at $30^{\circ} \mathrm{C}$, and 2) the lowest performance of NIs is at high temperatures $\left(>25^{\circ} \mathrm{C}\right)$ as suggested by prior studies [20]. DCD was mostly used in preliminary experiments, to determine a threshold concentration due to its low performance when compared to DMPP. DCD and DMPP at the rate of $0.2 \mathrm{mg} \mathrm{kg}^{-1}$ and $1.8 \mathrm{mg} \mathrm{kg}^{-1}$ of dry soil showed IE $>1 \%$ and $>50 \%$ in the most of selected soils, respectively. We selected $0.6 \mathrm{mg} \mathrm{kg}^{-1}$ and $1.2 \mathrm{mg} \mathrm{kg}^{-1}$ as intermediate points.

Based on preliminary experiments, soil slurry was prepared by mixing field-wet soil equal to the mass of $10 \mathrm{~g}$ dry soil with $40 \mathrm{~mL}$ of a medium solution containing $1 \mathrm{mmol} \mathrm{L}^{-1}$ potassium phosphate buffer and $0.2 \mathrm{~g} \mathrm{~L}^{-1}$ of ammonium sulfate. The DCD and DMPP was applied at the rate of $0.2 \mathrm{mg} \mathrm{kg}^{-1}$, $0.6 \mathrm{mg} \mathrm{kg}^{-1}, 1.2 \mathrm{mg} \mathrm{kg}^{-1}$, and $1.8 \mathrm{mg} \mathrm{kg}^{-1}$ of dry soil. All soil slurries were kept aerated by continuous shaking and incubated at as $17^{\circ} \mathrm{C}, 23^{\circ} \mathrm{C}, 30^{\circ} \mathrm{C}$ and $37^{\circ} \mathrm{C}$ for $24 \mathrm{~h}$. This time period was selected since (1) 24-h are reported to be sufficient to attain a substantial amount of ammonia oxidization for incubations, and (2) NI mineralization is reported to be negligible for a short period incubation. Nitrification potential of soil was measured by measuring nitrite accumulation rates over time using linear regression between concentrations and time. Each treatment was replicated three times and concentrations of mineral $\mathrm{N}\left(\mathrm{NO}_{2}{ }^{-}\right)$, extracted with $4 \mathrm{M} \mathrm{KCL}$ solution, were measured according to standard methods. The accumulation of $\mathrm{NO}_{2}{ }^{-}$over $24-\mathrm{h}$ was linear at all temperatures (data not shown), indicating that relative loss through alternate sinks was not significant for NP conditions.

\subsection{Data Analysis}

The IE was calculated by using mean values of ammonia oxidation in the control and after the application of DCD and DMPP for three replicated treatments. To compare the relative difference between IE at different measured temperatures for each application rate, the proportional inhibitory effect (PIE, \%) was calculated with the following formula:

$$
\text { PIE }(\%)=\frac{\text { Inhibitory effect at a specific temperature }}{\text { Inhibitory effect across all measured temperatures }} \times 100
$$


To provide a general overview of the samples, a principal component analysis (PCA) was developed. Raw IE data was used in the PCA calculation. Analysis of variance (ANOVA) with the Tukey-Kramer adjustment was used to test whether land-cover types and temperature significantly influence the nitrification rate after the application of DCD and DMPP. The variation in the required amount of NIs to achieve 50\% IE among soils, exhibiting different NP rates, was estimated by using polynomial regressions analysis (second-order). Firstly, the polynomial function was used to fit the equation to observed data and then the amount of NIs to achieve $50 \%$ IE was calculated by using the estimated parameters from the regression analysis. All statistical analysis was performed using $R$ programming language with base functions.

\section{Results}

\subsection{Nitrification Potential Among Land-Use Type and Temperatures}

NP rates were influenced by both land-use type and temperature gradient. Overall, the mean NP rates in cropped soils were $57.18 \%$ higher than those observed in non-cropped soils over the temperature gradient (Figure 1). The minimum nitrification rate for Taoyuan non-cropped soils where the maximum nitrification rate was associated with Chiayi cropped soils with cumulative nitrification rate for all temperature treatment was observed at $1.4 \mu \mathrm{g}$. $\mathrm{NO}_{2}{ }^{-} \mathrm{d}^{-1} \mathrm{~g}^{-1}$ of dry soil and $18.78 \mu \mathrm{g}$. $\mathrm{NO}_{2}{ }^{-} \mathrm{d}^{-1} \mathrm{~g}^{-1}$ of dry soil, respectively. Over-temperature gradient, NP rates increased with increasing temperature and declined significantly $(p<0.05)$ at $37^{\circ} \mathrm{C}$ for both types of soils. The nitrification rate peaked at $30^{\circ} \mathrm{C}$ where the associated nitrification rate varied from 0.51 to $3.39 \mathrm{NO}_{2}{ }^{-} \mathrm{d}^{-1} \mathrm{~g}^{-1}$ of dry soil and 2.83 to $6.85 \mu \mathrm{g}$. $\mathrm{NO}_{2}{ }^{-} \mathrm{d}^{-1} \mathrm{~g}^{-1}$ of dry soil for cropped and non-cropped soil, respectively. The exceptions to this are Pingtung non-cropped and Miaoli cropped soil, for which negligible differences between NP rates at $23^{\circ} \mathrm{C}$ and $30^{\circ} \mathrm{C}$ were observed. Moreover, there was no significant difference $(p>0.05)$ for $\mathrm{NP}$ rates at $17^{\circ} \mathrm{C}$ and $37^{\circ} \mathrm{C}$ for non-cropped soils, whereas the NP rates were significantly $(p<0.05)$ higher at $37^{\circ} \mathrm{C}$ compared to $17^{\circ} \mathrm{C}$ for cropped soils.
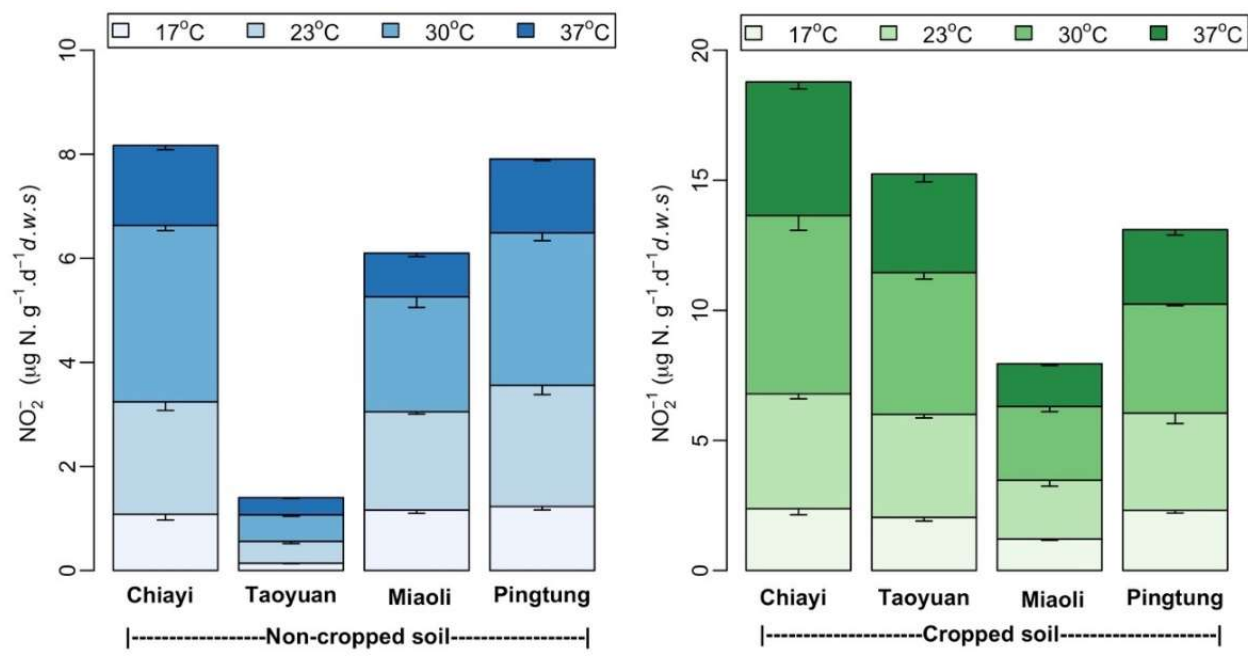

Figure 1. Soil nitrification potential among different cropped and non-cropped soils over a temperature gradient. Bars represent means ( \pm standard error of mean) for three replications.

\subsection{Effect of Soil NP Rates on NI Effectiveness}

\subsubsection{Variation Among NI Application Rates and Temperature}

The rate of ammonia oxidation after the application of DCD and DMPP at each application rate is shown in Figure 2 for both cropped and non-cropped soils. Soil NP rates, associated with land-use types, demonstrated a significant effect on IE associated with different DCD and DMPP application rates. Among cropped and non-cropped soils, Taoyuan non-cropped soils, which exhibited the lowest 
NP rates, showed the lowest ammonia oxidization, whereas Chiayi and Miaoli cropped soils, which exhibited the highest NP (Figure 2), showed the highest ammonia oxidization for DCD and DMPP when applied at the rate $<1.2 \mathrm{mg} \mathrm{kg}^{-1}$ of dry soil (Figure 2). By contrast, as the NI application rate increased among soils, soils with the lowest NP (mostly non-cropped soils) showed little to no statistical difference between DCD and DMPP for ammonia oxidization, especially at an application rate of $1.8 \mathrm{mg} \mathrm{kg}^{-1}$. However, ammonia oxidization among cropped soils was significantly different for DCD at high application rates, and for soils with the highest NP rates, IE was the lowest (Figure S1). No considerable difference was observed among cropped soils for DMPP, however. A similar trend was observed for IE within the cropped and non-cropped soil for different application rates, for soil with the lowest NP rates, IE was the highest (Figure S1). One exception to this is found in soils from Chiayi and Taoyuan that showed almost similar IE for DMPP at $30^{\circ} \mathrm{C}$ where the application rate was $1.2 \mathrm{mg} \mathrm{kg}^{-1}$ of dry soil despite a wider difference in the NP rates (Figure 1). Moreover, non-cropped soils with low NP rates did not seem to affect the IE of DCD and DMPP at high application rates. Cropped soils with high NP rates, however, demonstrated a considerable difference in IE among soils at high NI application rates (1.8 $\mathrm{mg} \mathrm{kg}^{-1}$ of dry soil), especially for DCD.
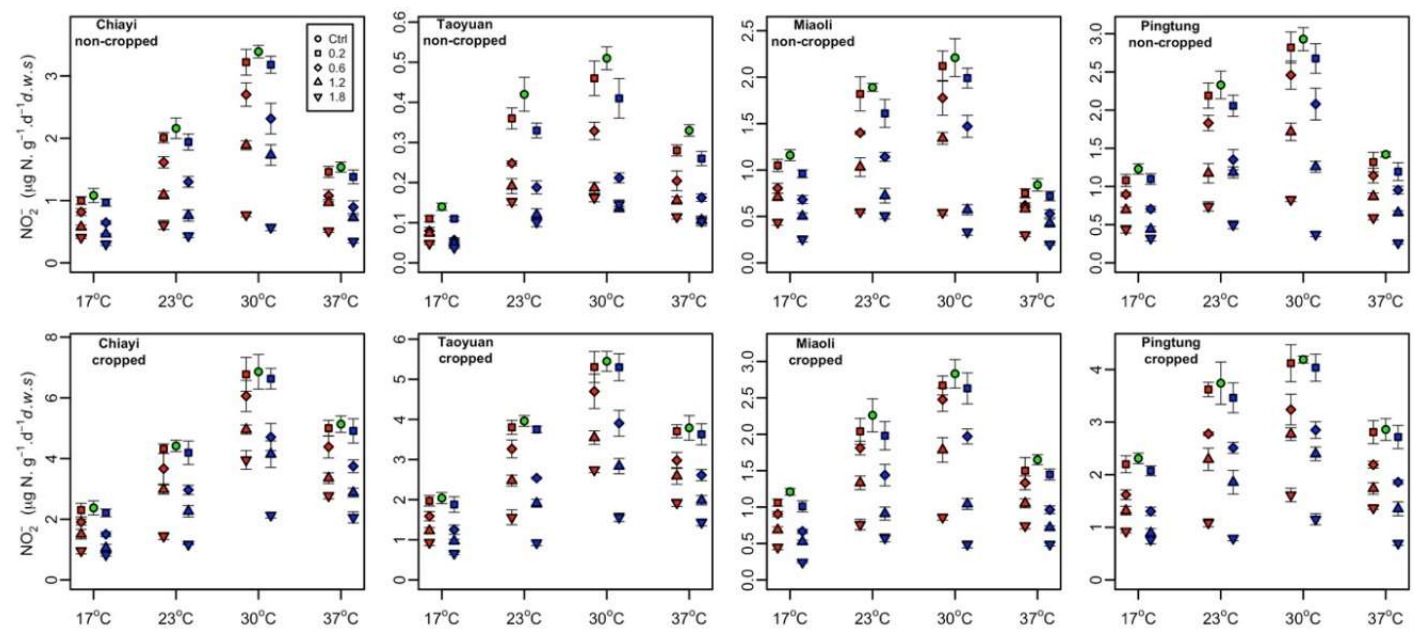

Figure 2. $\mathrm{NO}_{2}{ }^{-}$production after application of two nitrification inhibitors at four application rates over a temperature gradient. Red is dicyandiamide (DCD) and blue is 3,4-dimethylpyrazole phosphate (DMPP). Each point represents means ( \pm standard error of mean) for three replications.

We also measured the variation in the required amount of NIs to achieve 50\% IE among soils exhibiting different NP rates (Table S2). Regression analysis showed that Taoyuan non-cropped soils, with the lowest NP rates, can achieve an IE of almost 50\% for DCD and DMPP at application rates of $1.08,0.98,0.92$, and $1.05 \mathrm{mg} \mathrm{kg}^{-1}$ of dry soil and $0.14,0.37,0.36$, and $0.55 \mathrm{mg} \mathrm{kg}^{-1}$ of dry soil at 17,23 , 30 , and $37^{\circ} \mathrm{C}$, respectively. However, Chiayi cropped soils with its high NP rates would achieve a significantly lower IE ( $\leq 34.02 \%$ and $\leq 22.30 \%$ ) for both DCD and DMPP, at these application rates and temperatures, respectively. Among remaining soils, an IE of 50\% was usually achieved at application rates varies from 1.21 to $1.80 \mathrm{mg} \mathrm{kg}^{-1}$ of dry soil for DCD and 0.79 to $1.39 \mathrm{mg} \mathrm{kg}^{-1}$ of dry soil for DMPP. However, in a few exceptions (e.g., Chiayi cropped soil at $23^{\circ} \mathrm{C}$ and $30^{\circ} \mathrm{C}$ ), the application rate of DCD did not achieve an IE of 50\% at a maximum application rate of $1.8 \mathrm{mg} \mathrm{kg}^{-1}$ of dry soil and Taoyuan cropped soil at $37^{\circ} \mathrm{C}$, which required DCD $>1.8 \mathrm{mg} \mathrm{kg}^{-1}$ of dry soil to achieve an IE of $50 \%$.

To further understand how variation in soil NP rates affects the effectiveness of different application rates of DCD and DMPP, data were characterized as the ratio of NP rate to NI application rate. IE for both DCD and DMPP against NP-to-NI ratios is shown in Figure 3. The IE decreased with increasing NP-to-NI ratios and followed an exponential relationship to linear relationship, depending upon the application rates whereas the correlation was mostly stronger for DMPP $\left(R^{2}=0.56\right.$ to 0.85$)$ than DCD ( $R^{2}=0.45$ to 0.74 ) at application rates $<1.2 \mathrm{mg} \mathrm{kg}^{-1}$ of dry soil. By contrast, a poor correlation was 
observed for the highest application rate $\left(1.8 \mathrm{mg} \mathrm{kg}^{-1}\right.$ of dry soil), especially for DMPP $\left(R^{2}=0.04\right)$ than DCD $\left(R^{2}=0.25\right)$, further confirming that the IE is less likely to be affected by soil NP rates for DMPP at high application rates.
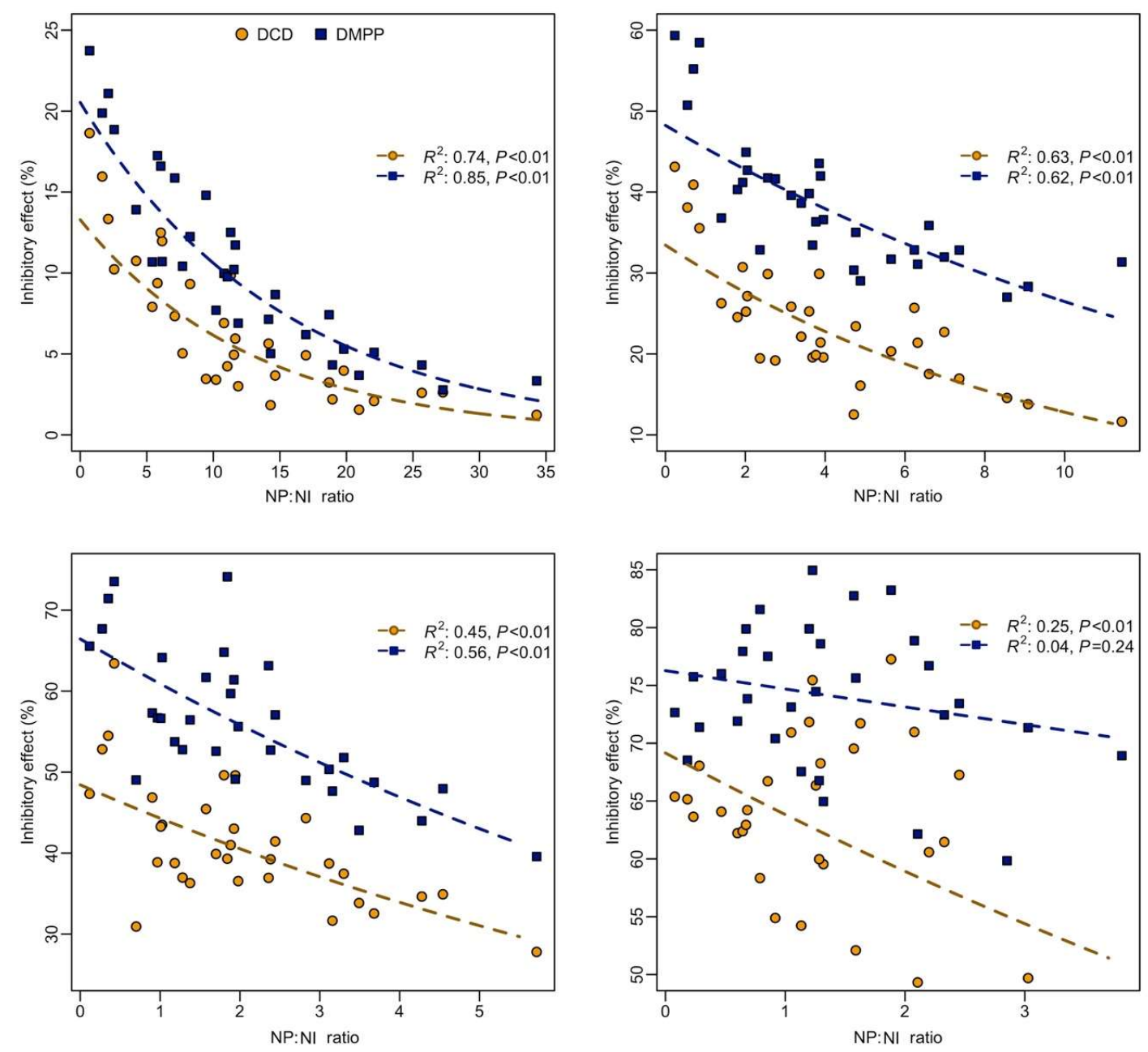

Figure 3. Influence of the different nitrification potential to NI application rates (NP-to-NI) ratios on inhibitory effect (\%) of DCD and DMPP.

The effect of soil NP rate and NI application rate on DCD and DMPP performance and their interactions was also assessed at four different temperatures. Proportional inhibition effect (PIE) for each application rate over temperature gradient was calculated to compare the DCD and DMPP performance at different temperature. Figure 4 shows the PIE of DCD and DMPP over the temperature gradient at four application rates. At a lower application rate $\left(0.2\right.$ and $0.6 \mathrm{mg} \mathrm{kg}^{-1}$ of dry soil) of DCD and DMPP, the maximum IE usually occurred at either $17^{\circ} \mathrm{C}$ or $37^{\circ} \mathrm{C}$, at which point an average decrease in IE of $2.61 \%$ to $8.77 \%$ was observed for DCD and $2.77 \%$ to $9.07 \%$ was observed for DMPP at $30{ }^{\circ} \mathrm{C}$. However, as the application rate increased to $1.2 \mathrm{mg} \mathrm{kg}^{-1}$ of dry soil, Taoyuan non-cropped soils showed the highest IE effect at $30^{\circ} \mathrm{C}$, whereas remaining soil samples showed a maximum PIE effect at $17^{\circ} \mathrm{C}$ and $23^{\circ} \mathrm{C}$ dependent upon soil NP rates (Figure 4). A similar trend was observed at a high application rate (1.8 $\mathrm{mg} \mathrm{kg}^{-1}$ of dry soil) where mostly non-cropped soils showed maximum PIE at $30^{\circ} \mathrm{C}$ at which point a corresponding highest NP rate was observed (Figure 1). For cropped soils, maximum IE was observed at $23^{\circ} \mathrm{C}$ when DCD was applied at the rate of $1.8 \mathrm{mg} \mathrm{kg}^{-1}$ of dry soil, whereas no significant difference in IE was observed for DMPP at a high application rate $\left(1.8 \mathrm{mg} \mathrm{kg}^{-1}\right.$ of dry soil) for both cropped and non-cropped soils (see Table S4 and S5). Moreover, there was no significant difference $(p<0.05)$ in PIE among $17^{\circ} \mathrm{C}$ and $37^{\circ} \mathrm{C}$ for non-cropped soils for all treatments 
except for DMPP at the application rate of $1.8 \mathrm{mg} \mathrm{kg}^{-1}$ of dry soil. By contrast, mostly application treatment showed no significant difference $(p>0.05)$ in PIE among cropped soil, and usually showed high NP rates at $17^{\circ} \mathrm{C}$ when compared to $37^{\circ} \mathrm{C}$ (see Tables S4 and S5), whereas corresponding NP rates were significantly lower at $17^{\circ} \mathrm{C}$ compared to $37^{\circ} \mathrm{C}$, suggesting that NP rates play a major role in shaping the IE of DCD and DMPP over-temperature gradient.
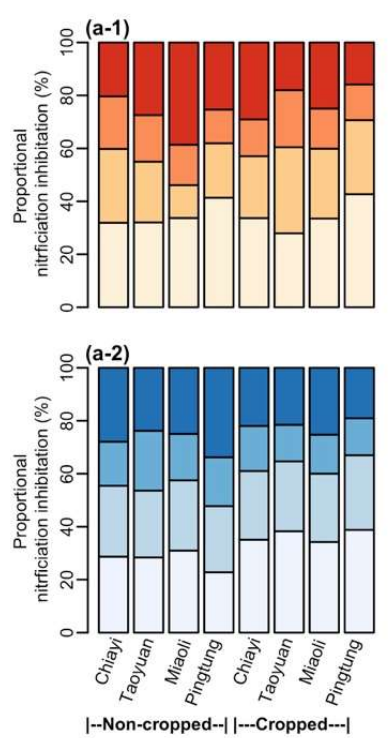
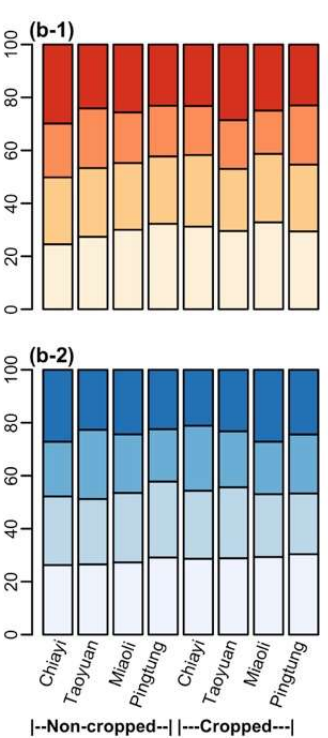
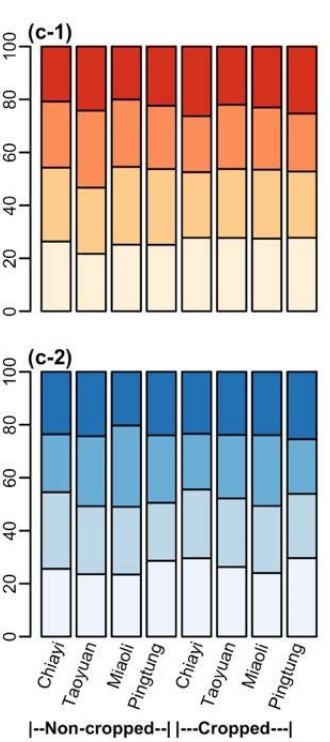
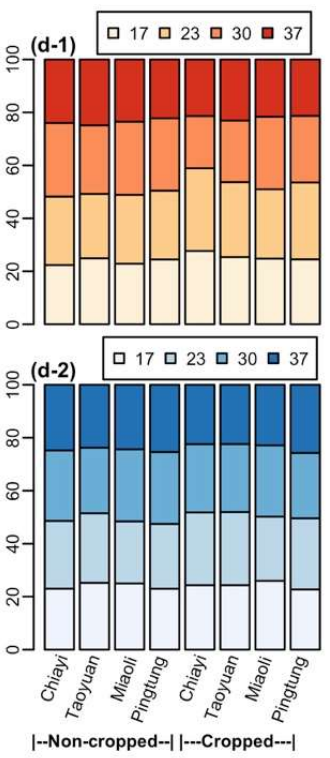

Figure 4. Proportional inhibitory effect expressed as the percentage among four different temperatures for different DCD and DMPP treatments. Note: (a-), (b-), (c-), and (d-) refer to $0.2 \mathrm{mg} \mathrm{kg}^{-1}, 0.6 \mathrm{mg} \mathrm{kg}^{-1}$, $1.2 \mathrm{mg} \mathrm{kg}^{-1}$, and $1.8 \mathrm{mg} \mathrm{kg}^{-1}$ of dry soil, respectively, where 1 refers to DCD and 2 refers to DMPP. Proportional IE was calculated by using mean $(n=3)$ values of absolute IE. The standard deviation for each treatment of control, DCD and DMPP, are presented in Figure 2.

A global overview of all these differences between NI application rates and temperature gradients can be seen in Figure 5 which depicts the variation according to principal components 1 (PCA1) and 2 (PCA2). These components accounted for 96.6 and $1.4 \%$ of the total variance, respectively. The soil NP and NI application rates are likely to have a major influence on the IE of both DCD and DMPP in soil. Even though there are some mixed samples, a pattern with three application rates $(0.2,0.6$, and $1.8 \mathrm{mg} \mathrm{kg}^{-1}$ of dry soil) can be observed in Figure 5. The highest variation was observed for an application rate of $1.2 \mathrm{mg} \mathrm{kg}^{-1}$. Moreover, Taoyuan non-cropped soils, which exhibited the lowest NP rates, was correlated with variation in the application rate of $1.2 \mathrm{mg} \mathrm{kg}^{-1}$ where remaining soil mostly showed correlation with $1.8 \mathrm{mg} \mathrm{kg}^{-1}$ of dry soil. However, distribution among temperature showed no patterns indicating a little influence of temperature in determining the IE of DCD and DMPP in different soils. 

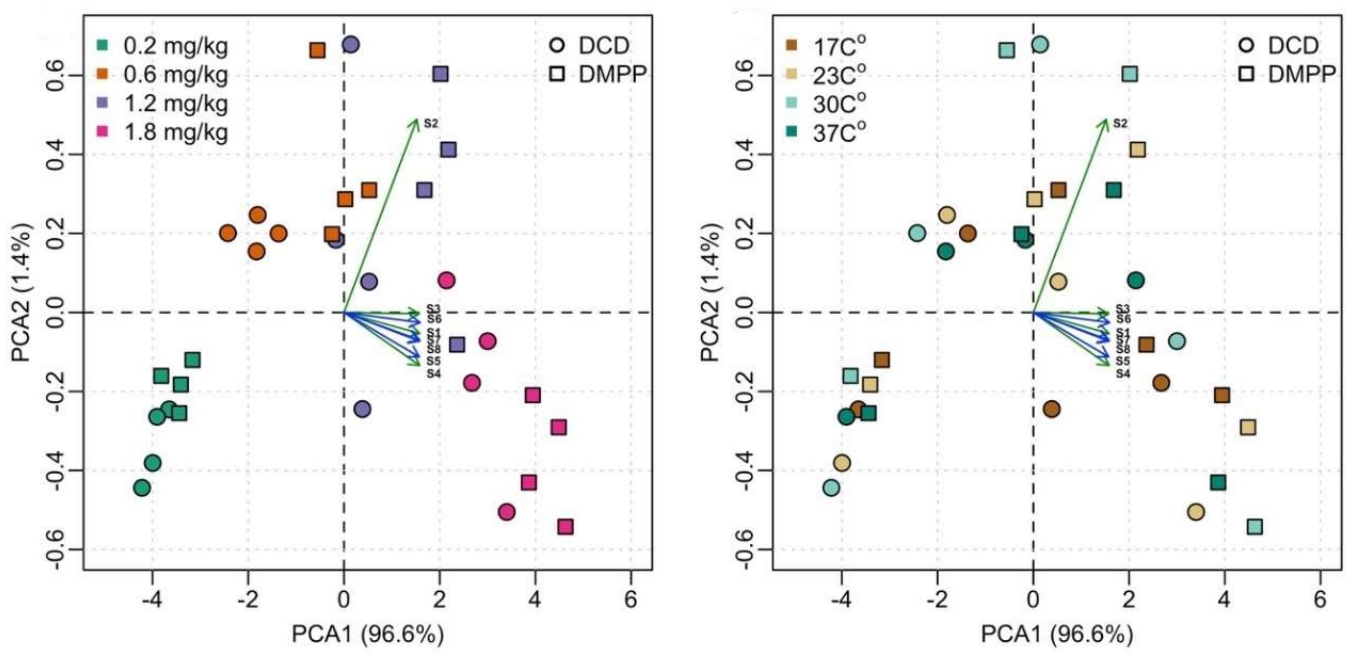

Figure 5. Biplot of PCA1 vs. PCA2 corresponding to a full-data principal component analysis (PCA) for inhibitory effect (IE) of DCD and DMPP in cropped and non-cropped soils. (S1, S2, S3, S4 represent soil samples collected from non-cropped fields and S5, S6, S7, and S8 represent soil samples collected from cropped fields in Chiayi, Taoyuan, Miaoli, and Pingtung, respectively).

\subsubsection{Variation among NI types}

The IEs of DMPP were considerably higher than nitrification inhibition carried out by DCD with respect to the control for all treatments. DCD-based IEs for all the combinations varied from $3.46 \%$ to $77.26 \%$ and $1.24 \%$ to $70.97 \%$ for non-cropped and cropped soils, respectively. DMPP-based IE varied from $6.20 \%$ to $87.27 \%$ and $2.78 \%$ to $82.75 \%$ for non-cropped and cropped soils, respectively. On average, the IE of DMPP was $11.46 \%$ higher than DCD for all combinations of temperature and application rates. However, among different application rates, the difference between DCD- and DMPP-based IE increased with an increasing application rate up to $1.2 \mathrm{mg} \mathrm{kg}^{-1}$ of dry soil and then slightly decreased $\left(4.01 \%, 14.78 \%, 15.23 \%\right.$, and $11.80 \%$ for $0.2,0.6,1.2$, and $1.8 \mathrm{mg} \mathrm{kg}^{-1}$ of dry soil, respectively).

We also measured the difference in nitrification inhibition among cropped and non-cropped soils to see if the effectiveness of NIs varies among land-use types. The result showed that both DCD and DMPP have relatively higher performance in non-cropped soils than cropped soils at low application rates. However, the difference in DMPP performance among cropped and non-cropped soils was higher than in DCD (6.81\% and 4.35\%, respectively) at the application rate of $0.2 \mathrm{mg} \mathrm{kg}^{-1}$ of dry soil. By contrast, DCD showed a higher difference among cropped and non-cropped soils than DMPP $(9.28 \%$ and $5.50 \%$, respectively) at the application rate of $1.8 \mathrm{mg} / \mathrm{kg}$ of dry soil. Regardless, the difference in DCD and DMPP performance was similar at the application rates of 0.6 and $1.2 \mathrm{mg} \mathrm{kg}^{-1}$ of dry soil.

\section{Discussion}

Studying the effect of soil nitrification potential on the performance of NIs is an issue of major interest. Our study documents the distribution of IEs for DCD and DMPP, explores how the effectiveness of application rates diverges for different soil NP rates over a temperature gradient, and examines the relationships between those variables. To our knowledge, no published work has yet investigated these interactions for different cropped and non-cropped soils across a wider temperature gradient $\left(17^{\circ} \mathrm{C}\right.$ to $\left.37^{\circ} \mathrm{C}\right)$.

We found that the IE of DCD and DMPP can be organized according to soil NP and NI application rates. The observed negative correlation between NI application rate and the ammonia oxidization rate corroborates with the prevailing framework, which asserts that the nitrification rate and emission factor decrease with an increased NI application rate $[7,13,24,34]$. Differing from the previous framework, we observed a decrease in the effectiveness of NI with increasing NP rates, especially when the application rate is $<1.2 \mathrm{mg} \mathrm{kg}^{-1}$ of dry soil. Although the literature is thin in this area, soil nitrification rates and 
associated IEs by application of NIs have been reported for a variety of soils, though usually at a fixed application rate (which partially corroborates with our findings). Supporting our results, Suter et al. (2010) [42] found the inhibitory effect for $\mathrm{NO}_{3}$ accumulation, after application of DCD and DMPP at the rates of $3.8 \mathrm{mg} \mathrm{kg}^{-1}$ and $0.71 \mathrm{mg} \mathrm{kg}^{-1}$ of soil, was negligible on topsoil where the soil ammonia oxidation was lower when compared to subsoil, (18 $\mathrm{mg} \mathrm{kg}^{-1} \mathrm{~d}^{-1}$ and $4 \mathrm{mg} \mathrm{kg}^{-1} \mathrm{~d}^{-1}$, respectively). A similar trend was observed by Torralbo et al. (2017) [43] who found a reduction in IE when ammonia oxidation increased due to aerobic conditions. However, our results contradict the work of Barth et al. (2001) [44] who found high effectiveness of DMPP in soils that exhibited high NP rates compared to the soils where NP rates were relatively lower when incubated for $5 \mathrm{~h}$ at different DMPP application rates. One major reason for this variation may be associated with the short incubation time since incubation for 1 day is essential to study the activities of ammonia oxidizers [3,40]. Regardless, we found that IE is less likely to be influenced by a small variation in soil NP caused by soil type, or measured temperature at higher NI application rates. A similar trend was reported by McGeough et al. (2016) who observed a high IE in arable soil compared to grasslands, however, IE did not vary accordingly to soil NP rates at a DCD application rate of $10 \mathrm{mg} \mathrm{g}^{-1}$ of dry soil. This similarity in results is likely due to the high application rate of NI which invalidates the effect of NP rates in different soils. These observations were also true for the soils with a moderate range of nitrification which showed no significant difference for IE despite the considerable difference in the NP rates. This phenomenon may be associated with the difference between NI application rates, since a narrow difference between application rates may be required to observe a difference in IE among these soils associated with the NP rates. Taken together, in absence of soil NP data, a high application rate may be required to compensate for the IE in a variety of soils that exert different NPs, as suggested in a recent metanalysis which reports that an application rate of DCD $>5 \mathrm{~kg} \mathrm{ha}^{-1}$ is necessary to achieve substantial IE [24].

The performance of both DCD and DMPP was higher in non-cropped soil than in the cropped systems. This observation was true for all temperatures varying from $17^{\circ} \mathrm{C}$ to $37^{\circ} \mathrm{C}$. The variation in IEs among land-use type is consistent with the prevailing framework, which asserts that the performance of DCD and DMPP varies among the land-use type. In agreement with Gilsanz et al. (2016) and Akiyama et al. (2010), in this study DCD contributed to a greater IE in non-cropped soils. However, IE of DMPP was also higher in non-croplands which partially contradicts Gilsanz et al. (2016) who predicted high effectiveness of DMPP in cropped uplands. One of the major reasons for the high performances of both DCD and DMPP in non-cropped soil is due to the lower soil NP rates in non-cropped soils, compared to cropped soils. However, DMPP's higher performance, compared to DCD, may be due to low application rates. This is because, at a low application rate, the high performance of DMMP may inhibit more oxidization in non-cropped soils than in cropped soils, resulting in a wider difference in performance. Similarly, at the high application rate, DMPP performance is less likely to be influenced by soil NP rates and showed a smaller difference in performance among land-use types than DCD. These factors likely contribute to variation in DCD and DMPP performance at different application rates among different landcover types.

At the outset of this study, we expected to find that IE is lower at $30{ }^{\circ} \mathrm{C}$ since both cropped and non-cropped soil showed high NP at $30^{\circ} \mathrm{C}$. However, we found that the maximum IE over a temperature gradient varied from $17^{\circ} \mathrm{C}$ to $37^{\circ} \mathrm{C}$ depending upon the soil NP and NI application rates. In general, we found high IE at $17^{\circ} \mathrm{C}$ and $37^{\circ} \mathrm{C}$ for lower application rates, whereas high IE was observed at $23^{\circ} \mathrm{C}$ and $37^{\circ} \mathrm{C}$ for high application rates. This phenomenon is likely related to the magnitude of AMO activity at different temperatures since, at a low NI application rate, lower $\mathrm{NP}$ rates at $17^{\circ} \mathrm{C}$ and $37^{\circ} \mathrm{C}$ have more potential to reduce ammonia oxidation and so exhibit a high inhibition effect compared to $30^{\circ} \mathrm{C}$. By contrast, soils that experience high AMO enzyme activity at $23{ }^{\circ} \mathrm{C}$ and $30{ }^{\circ} \mathrm{C}$ would experience greater variation for nitrification (between the control and NI treated soil), compared to similar soil at below- and above-temperatures at high NI application rates $\left(1.8 \mathrm{mg} / \mathrm{kg}\right.$ of dry soil). Consequently, relatively high NP rates at $23^{\circ} \mathrm{C}$ and $30^{\circ} \mathrm{C}$ at high NI application rates resulted in high IE. These observations partially corroborate with recent meta-analysis [7] on 
the effectiveness of NIs among various land-use types with different $\mathrm{N}$ application rates (substrate levels). The study reported a high IE for grassland soils, which showed high emission factor among other land-use types. However, a relatively small IE in cropped soils with high NP rates at $30^{\circ} \mathrm{C}$, at high application rates, suggests that an increase in the application is required to further inhibit the activity. These factors likely contribute to the changing maximum inhibition at different temperatures, among different application rates.

The association of IE, at $17^{\circ} \mathrm{C}$ and $37^{\circ} \mathrm{C}$, with NP rates, revealed the potential of NI by DCD and DMPP at a wider temperature range. Previous studies generally found that NI effectiveness decreases with increasing temperature [18-20], results which do not match our ammonia oxidization inhibition results completely. We did find variation in the performance of NIs across a temperature gradient, however, no significant differences in the reduction of NP rates between a lower temperature $\left(17^{\circ} \mathrm{C}\right)$ and a higher temperature $\left(37^{\circ} \mathrm{C}\right)$ were detected for soils with lower NP rates. However, in recent studies, both DCD and DMPP are reported to majorly target the activity of AOB but not AOA for ammonia oxidization. Since AOA is a major player in soil nitrification at temperatures $>35^{\circ} \mathrm{C}[3,45-47]$, whereas $\mathrm{AOB}$ is more active at temperatures $\leq 30^{\circ} \mathrm{C}$ [48,49], a high IE effect at both lower and high temperature, in this study, demonstrate the potential of DCD and DMPP to inhibit the nitrification activity carried out by both $\mathrm{AOA}$ and $\mathrm{AOB}$ in short term incubation. This difference in results is likely due to the persistence of DCD and DMPP which could last for a few weeks to months, depending upon the soil temperature. Therefore, variation in the persistence of NIs in soil may lead to differential nitrification fluxes under different temperature conditions [50]. However, the lower NP rates at $37^{\circ} \mathrm{C}$, compared to $17^{\circ} \mathrm{C}$, for cropped soils was associated with NP rates which were significantly higher at $37^{\circ} \mathrm{C}$ compared to $17^{\circ} \mathrm{C}$, and an increase in NI concentration would eventually increase the IE at $37^{\circ} \mathrm{C}$ for cropped soil (high NP rates) as observed for non-cropped soils.

The variation in the persistence of NI may explain the relatively small difference in DCD and DMPP performance among different application rates and temperatures. The IE of DMPP was higher than DCD and the difference was more significant for non-cropped soils, which is consistent with the known dependence of N flux inhibition on NI type [21]. However, our results contradict (with a known magnitude of) the effectiveness limitation of DCD compared to DMPP. Previous studies suggest that relatively consistent IEs, or better IEs, can be achieved when the DMPP application rate was $\approx 10$ times less than DCD [50-52]. Although the results presented here partially support previous studies' results, the difference in IEs between DCD and DMPP, across all application rates, was never greater than $15.23 \%$ for the same NI application rates. This variation in results is likely due to the duration of incubation which affects NI persistence, sorption rate, and NI degradation by microbial assimilation [29,32,33,52]. Since DMPP is more persistent in soil than DCD [52], the relatively fast reduction of DCD in soil may reduce its effect to inhibit ammonia oxidizer activities, and so may have a low inhibition effect as reported in previous studies. On the other hand, a short incubation in this study did not affect the NI persistence and showed relatively small differences among DCD- and DMPP-based IEs. From these results, it can be concluded that the short-term inhibitory effect of DCD and DMPP was influenced by the soil NP rates, especially for DCD. Therefore, soil NP rates can be used to predict the short-term inhibitory effect of NI in different soil which may help to optimize the NI application rate to make them more economically viable for agronomical purpose. However, it remains to be seen if an interaction between the performances of DCD and DMPP and soil nitrification potential from other soil environments, will yield confirmatory results. Yet, IEs based on different application rates over a temperature gradient will add to our understanding at both laboratory and field levels.

\section{Conclusions}

The effect of soil NP on the performance of DCD and DMPP was observed in cropped and non-cropped soils, that were incubated over a temperature gradient. Our study suggests that the effectiveness of different application rates of DCD and DMPP, among land-use types and over-temperature gradient, is sensitive to soil NP rates. Among cropped and non-cropped soil, 
soil NP rates varied and the IE decreased with an increasing soil NP to NI ratio, especially for DCD. We suggest that, as soil NP increases, the soil requires a higher concertation of NIs to attain a similar IE, which could also be achieved with lower NI application rates in soil exerting relatively lower ammonia oxidation rates. However, in the absence of soil NP data, a high application rate will require that one compensate the IE in variety soils exerting different nitrification potentials. To be effective, soil NP rates must be considered while proposing an application rate of DCD and DMPP in different soils to optimize the effectiveness of NIs.

Supplementary Materials: The following are available online at http://www.mdpi.com/2073-4395/9/10/599/s1, Figure S1: Inhibitory effect of DCD and DMPP at four application rates over a temperature gradient, Table S1: Physicochemical prosperities of cropped and non-cropped soil samples, Table S2: The required amount of DCD and DMPP ( $\mathrm{mg} / \mathrm{kg}$ of dry soil) to achieve the inhibitory effect $\approx 50 \%$ for non-cropped and cropped soils, Table S3: Coefficient of determination for model fit to achieve the inhibitory effect $\approx 50 \%$ for non-cropped and cropped soils, Table S4: ANOVA analysis with Tukey's post hoc test to assess the significant difference in proportional inhibitory effect (PIE) among measured temperatures for non-cropped soils, Table S5: ANOVA analysis with Tukey's post hoc test to assess the significant difference in proportional inhibitory effect (PIE) among measured temperatures for cropped soils.

Author Contributions: The scope of this study was developed by H.M. and Y.-P.L. The first manuscript draft was written by H.M. and Y.-P.L., and was substantially revised by Y.-P.L.

Funding: This research was financially supported by the National Taiwan University (Nos. NTUCC-107L892608 and NTUCC-108L892608). The study is partially supported by the Council of Agriculture, Taiwan (No. 108AS-4.2.2-ST-a1) and Ministry of Science and Technology (No. 108-2918-I-002 -038).

Acknowledgments: The authors would like to thank Chiao-Ming Lin for her experimental support and to Joy R. Petway for her Professional language Editing.

Conflicts of Interest: The authors declare no conflict of interest.

\section{References}

1. Coskun, D.; Britto, D.T.; Shi, W.; Kronzucker, H.J. Nitrogen transformations in modern agriculture and the role of biological nitrification inhibition. Nat. Plants 2017, 3, 17074. [CrossRef] [PubMed]

2. Taylor, A.E.; Myrold, D.D.; Bottomley, P.J. Temperature affects the kinetics of nitrite oxidation and nitrification coupling in four agricultural soils. Soil Biol. Biochem. 2019, 107523. [CrossRef]

3. Taylor, A.E.; Giguere, A.T.; Zoebelein, C.M.; Myrold, D.D.; Bottomley, P.J. Modeling of soil nitrification responses to temperature reveals thermodynamic differences between ammonia-oxidizing activity of archaea and bacteria. ISME J. 2017, 11, 896-908. [CrossRef] [PubMed]

4. Shaw, L.J.; Nicol, G.W.; Smith, Z.; Fear, J.; Prosser, J.I.; Baggs, E.M. Nitrosospira spp. can produce nitrous oxide via a nitrifier denitrification pathway. Environ. Microbiol. 2006, 8, 214-222. [CrossRef] [PubMed]

5. Firestone, M.K.; Davidson, E.A. Microbiological basis of NO and N2O production and consumption in soil. Exch. Trace Gases Terr. Ecosyst. Atmos. 1989, 47, 7-21.

6. Font-Palma, C. Methods for the Treatment of Cattle Manure-A Review. C J. Carbon Res. 2019, 5, 27. [CrossRef]

7. Gilsanz, C.; Báez, D.; Misselbrook, T.H.; Dhanoa, M.S.; Cárdenas, L.M. Development of emission factors and efficiency of two nitrification inhibitors, DCD and DMPP. Agric. Ecosyst. Environ. 2016, 216, 1-8. [CrossRef]

8. Lam, S.K.; Suter, H.; Mosier, A.R.; Chen, D. Using nitrification inhibitors to mitigate agricultural N2O emission: A double-edged sword? Glob. Chang. Biol. 2017, 23, 485-489. [CrossRef] [PubMed]

9. Friedl, J.; Scheer, C.; Rowlings, D.W.; Mumford, M.T.; Grace, P.R. The nitrification inhibitor DMPP (3, 4-dimethylpyrazole phosphate) reduces N2 emissions from intensively managed pastures in subtropical Australia. Soil Biol. Biochem. 2017, 108, 55-64. [CrossRef]

10. Rose, T.J.; Wood, R.H.; Rose, M.T.; Van Zwieten, L. A re-evaluation of the agronomic effectiveness of the nitrification inhibitors DCD and DMPP and the urease inhibitor NBPT. Agric. Ecosyst. Environ. 2018, 252, 69-73. [CrossRef]

11. Dai, Y.; Di, H.J.; Cameron, K.C.; He, J.Z. Effects of nitrogen application rate and a nitrification inhibitor dicyandiamide on ammonia oxidizers and $\mathrm{N} 2 \mathrm{O}$ emissions in a grazed pasture soil. Sci. Total Environ. 2013, 465, 125-135. [CrossRef] 
12. Singh, J.; Saggar, S.; Giltrap, D.L.; Bolan, N.S. Decomposition of dicyandiamide (DCD) in three contrasting soils and its effect on nitrous oxide emission, soil respiratory activity, and microbial biomass-An incubation study. Soil Res. 2008, 46, 517-525. [CrossRef]

13. Zaman, M.; Blennerhassett, J.D. Effects of the different rates of urease and nitrification inhibitors on gaseous emissions of ammonia and nitrous oxide, nitrate leaching and pasture production from urine patches in an intensive grazed pasture system. Agric. Ecosyst. Environ. 2010, 136, 236-246. [CrossRef]

14. Keener, W.K.; Arp, D.J. Kinetic studies of ammonia monooxygenase inhibition in Nitrosomonas europaea by hydrocarbons and halogenated hydrocarbons in an optimized whole-cell assay. Appl. Environ. Microbiol. 1993, 59, 2501-2510.

15. Singh, S.N.; Verma, A. Environmental review: The potential of nitrification inhibitors to manage the pollution effect of nitrogen fertilizers in agricultural and other soils: A review. Environ. Pract. 2007, 9, 266-279. [CrossRef]

16. Di, H.J.; Cameron, K.C. Inhibition of ammonium oxidation by a liquid formulation of 3, 4-Dimethylpyrazole phosphate (DMPP) compared with a dicyandiamide (DCD) solution in six New Zealand grazed grassland soils. J. Soils Sediments 2011, 11, 1032. [CrossRef]

17. Kong, X.; Duan, Y.; Schramm, A.; Eriksen, J.; Petersen, S.O. 3, 4-Dimethylpyrazole phosphate (DMPP) reduces activity of ammonia oxidizers without adverse effects on non-target soil microorganisms and functions. Appl. Soil Ecol. 2016, 105, 67-75. [CrossRef]

18. Menéndez, S.; Barrena, I.; Setien, I.; González-Murua, C.; Estavillo, J.M. Efficiency of nitrification inhibitor DMPP to reduce nitrous oxide emissions under different temperature and moisture conditions. Soil Biol. Biochem. 2012, 53, 82-89. [CrossRef]

19. Irigoyen, I.; Muro, J.; Azpilikueta, M.; Aparicio-Tejo, P.; Lamsfus, C. Ammonium oxidation kinetics in the presence of nitrification inhibitors DCD and DMPP at various temperatures. Soil Res. 2003, 41, 1177-1183. [CrossRef]

20. Lan, T.; Suter, H.; Liu, R.; Yuan, S.; Chen, D. Effects of nitrification inhibitors on gross N nitrification rate, ammonia oxidizers, and $\mathrm{N}_{2} \mathrm{O}$ production under different temperatures in two pasture soils. Environ. Sci. Pollut. Res. 2018, 25, 28344-28354. [CrossRef]

21. Chen, Q.; Qi, L.; Bi, Q.; Dai, P.; Sun, D.; Sun, C.; Liu, W.; Lu, L.; Ni, W.; Lin, X. Comparative effects of 3, 4-dimethylpyrazole phosphate (DMPP) and dicyandiamide (DCD) on ammonia-oxidizing bacteria and archaea in a vegetable soil. Appl. Microbiol. Biotechnol. 2015, 99, 477-487. [CrossRef] [PubMed]

22. Dong, X.X.; Zhang, L.L.; Wu, Z.J.; Li, D.P.; Shang, Z.C.; Gong, P. Effects of the nitrification inhibitor DMPP on soil bacterial community in a Cambisol in northeast China. J. Soil Sci. Plant Nutr. 2013, 13, 580-591. [CrossRef]

23. Di, H.J.; Cameron, K.C. Nitrous oxide emissions from two dairy pasture soils as affected by different rates of a fine particle suspension nitrification inhibitor, dicyandiamide. Biol. Fertil. Soils 2006, 42, 472-480. [CrossRef]

24. Ruser, R.; Schulz, R. The effect of nitrification inhibitors on the nitrous oxide (N2O) release from agricultural soils-A review. J. Plant Nutr. Soil Sci. 2015, 178, 171-188. [CrossRef]

25. Vitale, L.; Tedeschi, A.; Polimeno, F.; Ottaiano, L.; Maglione, G.; Arena, C.; De Marco, A.; Magliulo, V. Water regime affects soil $\mathrm{N} 2 \mathrm{O}$ emission and tomato yield grown under different types of fertilisers. Ital. J. Agron. 2018, 74-79. [CrossRef]

26. Vitale, L.; Ottaiano, L.; Polimeno, F.; Maglione, G.; Amato, U.; Arena, C.; Di Tommasi, P.; Mori, M.; Magliulo, V. Effects of 3, 4-dimethylphyrazole phosphate-added nitrogen fertilizers on crop growth and $\mathrm{N} 2 \mathrm{O}$ emissions in Southern Italy. Plant Soil Environ. 2013, 59, 517-523. [CrossRef]

27. Akiyama, H.; Yan, X.; Yagi, K. Evaluation of effectiveness of enhanced-efficiency fertilizers as mitigation options for $\mathrm{N} 2 \mathrm{O}$ and $\mathrm{NO}$ emissions from agricultural soils: Meta-analysis. Glob. Chang. Biol. 2010, 16, 1837-1846. [CrossRef]

28. Barth, G.; Von Tucher, S.; Schmidhalter, U. Effectiveness of 3, 4-dimethylpyrazole phosphate as nitriflcation inhibitor in soil as influenced by inhibitor concentration, application form, and soil matric potential. Pedosphere 2008, 18, 378-385. [CrossRef]

29. Guardia, G.; Marsden, K.A.; Vallejo, A.; Jones, D.L.; Chadwick, D.R. Determining the influence of environmental and edaphic factors on the fate of the nitrification inhibitors DCD and DMPP in soil. Sci. Total Environ. 2018, 624, 1202-1212. [CrossRef] [PubMed] 
30. McGeough, K.L.; Watson, C.J.; Müller, C.; Laughlin, R.J.; Chadwick, D.R. Evidence that the efficacy of the nitrification inhibitor dicyandiamide (DCD) is affected by soil properties in UK soils. Soil Biol. Biochem. 2016, 94, 222-232. [CrossRef]

31. Kelliher, F.M.; Clough, T.J.; Clark, H.; Rys, G.; Sedcole, J.R. The temperature dependence of dicyandiamide (DCD) degradation in soils: A data synthesis. Soil Biol. Biochem. 2008, 40, 1878-1882. [CrossRef]

32. Chaves, B.; Opoku, A.; De Neve, S.; Boeckx, P.; Van Cleemput, O.; Hofman, G. Influence of DCD and DMPP on soil N dynamics after incorporation of vegetable crop residues. Biol. Fertil. Soils 2006, 43, 62-68. [CrossRef]

33. Marsden, K.A.; Marín-Martínez, A.J.; Vallejo, A.; Hill, P.W.; Jones, D.L.; Chadwick, D.R. The mobility of nitrification inhibitors under simulated ruminant urine deposition and rainfall: A comparison between DCD and DMPP. Biol. Fertil. Soils 2016, 52, 491-503. [CrossRef]

34. Gong, P.; Zhang, L.; Wu, Z.; Shang, Z.; Li, D. Does the nitrification inhibitor dicyandiamide affect the abundance of ammonia-oxidizing bacteria and archaea in a Hap-Udic Luvisol? J. Soil Sci. Plant Nutr. 2013, 13, 35-42. [CrossRef]

35. Gong, P.; Zhang, L.L.; WU, Z.J.; Chen, Z.H.; Chen, L.J. Responses of ammonia-oxidizing bacteria and archaea in two agricultural soils to nitrification inhibitors DCD and DMPP: A pot experiment. Pedosphere 2013, 23, 729-739. [CrossRef]

36. Stempfhuber, B.; Engel, M.; Fischer, D.; Neskovic-Prit, G.; Wubet, T.; Schöning, I.; Gubry-Rangin, C.; Kublik, S.; Schloter-Hai, B.; Rattei, T. pH as a driver for ammonia-oxidizing archaea in forest soils. Microb. Ecol. 2015, 69, 879-883. [CrossRef]

37. Bouskill, N.J.; Eveillard, D.; Chien, D.; Jayakumar, A.; Ward, B.B. Environmental factors determining ammonia-oxidizing organism distribution and diversity in marine environments. Environ. Microbiol. 2012, 14, 714-729. [CrossRef]

38. Erguder, T.H.; Boon, N.; Wittebolle, L.; Marzorati, M.; Verstraete, W. Environmental factors shaping the ecological niches of ammonia-oxidizing archaea. FEMS Microbiol. Rev. 2009, 33, 855-869. [CrossRef] [PubMed]

39. Mukhtar, H.; Lin, Y.P.; Anthony, J. Ammonia Oxidizing Archaea and Bacteria in East Asian Paddy Soils-A Mini Review. Environments 2017, 4, 84.

40. Duan, P.; Wu, Z.; Zhang, Q.; Fan, C.; Xiong, Z. Thermodynamic responses of ammonia-oxidizing archaea and bacteria explain $\mathrm{N}_{2} \mathrm{O}$ production from greenhouse vegetable soils. Soil Biol. Biochem. 2018, 120, 37-47. [CrossRef]

41. Mukhtar, H.; Lin, Y.P.; Lin, C.M.; Petway, J.R. Assessing Thermodynamic Parameter Sensitivity for Simulating Temperature Response of Soil Nitrification. Environ. Sci. Process. Impacts 2019, 21, 1596-1608. [CrossRef] [PubMed]

42. Suter, H.; Chen, D.; Li, H.; Edis, R.; Walker, C. Comparison of the ability of the nitrification inhibitors DCD and DMPP to reduce nitrification and $\mathrm{N}_{2} \mathrm{O}$ emissions from nitrogen fertilisers. In Proceedings of the 19th World Congress of Soils Science, Brisbane, Australia, 1-6 August 2010; pp. 1-6.

43. Torralbo, F.; Menéndez, S.; Barrena, I.; Estavillo, J.M.; Marino, D.; González-Murua, C. Dimethyl pyrazol-based nitrification inhibitors effect on nitrifying and denitrifying bacteria to mitigate $\mathrm{N}_{2} \mathrm{O}$ emission. Sci. Rep. 2017, 7, 13810. [CrossRef] [PubMed]

44. Barth, G.; Von Tucher, S.; Schmidhalter, U. Influence of soil parameters on the effect of 3 , 4-dimethylpyrazole-phosphate as a nitrification inhibitor. Biol. Fertil. Soils 2001, 34, 98-102.

45. Tourna, M.; Stieglmeier, M.; Spang, A.; Könneke, M.; Schintlmeister, A.; Urich, T.; Engel, M.; Schloter, M.; Wagner, M.; Richter, A. Nitrososphaera viennensis, an ammonia oxidizing archaeon from soil. Proc. Natl. Acad. Sci. USA 2011, 108, 8420-8425. [CrossRef] [PubMed]

46. Lehtovirta-Morley, L.E.; Ge, C.; Ross, J.; Yao, H.; Nicol, G.W.; Prosser, J.I. Characterisation of terrestrial acidophilic archaeal ammonia oxidisers and their inhibition and stimulation by organic compounds. FEMS Microbiol. Ecol. 2014, 89, 542-552. [CrossRef]

47. Lehtovirta-Morley, L.E.; Ross, J.; Hink, L.; Weber, E.B.; Gubry-Rangin, C.; Thion, C.; Prosser, J.I.; Nicol, G.W. Isolation of 'Candidatus Nitrosocosmicus franklandus', a novel ureolytic soil archaeal ammonia oxidiser with tolerance to high ammonia concentration. FEMS Microbiol. Ecol. 2016, 92, fiw057. [CrossRef]

48. Jiang, Q.Q.; Bakken, L.R. Comparison of Nitrosospira strains isolated from terrestrial environments. FEMS Microbiol. Ecol. 1999, 30, 171-186. [CrossRef] 
49. Jones, R.D.; Morita, R.Y. Low-temperature growth and whole-cell kinetics of a marine ammonium oxidizer. Mar. Ecol. Prog. Ser. 1985, 21, 239-243. [CrossRef]

50. Zerulla, W.; Barth, T.; Dressel, J.; Erhardt, K.; von Locquenghien, K.H.; Pasda, G.; Rädle, M.; Wissemeier, A. 3, 4-Dimethylpyrazole phosphate (DMPP)—A new nitrification inhibitor for agriculture and horticulture. Biol. Fertil. Soils 2001, 34, 79-84. [CrossRef]

51. Benckiser, G.; Christ, E.; Herbert, T.; Weiske, A.; Blome, J.; Hardt, M. The nitrification inhibitor 3, 4-dimethylpyrazole-phosphat (DMPP)-quantification and effects on soil metabolism. Plant Soil 2013, 371, 257-266. [CrossRef]

52. Weiske, A.; Benckiser, G.; Ottow, J.C.G. Effect of the new nitrification inhibitor DMPP in comparison to DCD on nitrous oxide $(\mathrm{N} 2 \mathrm{O})$ emissions and methane $(\mathrm{CH} 4)$ oxidation during 3 years of repeated applications in field experiments. Nutr. Cycl. Agroecosyst. 2001, 60, 57-64. [CrossRef]

(C) 2019 by the authors. Licensee MDPI, Basel, Switzerland. This article is an open access article distributed under the terms and conditions of the Creative Commons Attribution (CC BY) license (http://creativecommons.org/licenses/by/4.0/). 